\section{Water Power for a Clean Energy Future}

Water power is the nation's largest source of clean, domestic, renewable energy. Harnessing energy from rivers, manmade waterways, and oceans to generate electricity for the nation's homes and businesses can help secure America's energy future. Water power technologies fall into two broad categories: conventional hydropower and marine and hydrokinetic technologies. Conventional hydropower facilities include runof-the-river, storage, and pumped storage. Most conventional hydropower plants use a diversion structure, such as a dam, to capture water's potential energy via a turbine for electricity generation. Marine and hydrokinetic technologies obtain energy from waves, tides, ocean currents, free-flowing rivers, streams and ocean thermal gradients to generate electricity.

The United States has abundant water power resources, enough to meet a large portion of the nation's electricity demand. Conventional hydropower generated 257 million megawatt-hours (MWh) of electricity in 2010 and provides $6-7 \%$ of all electricity in the United States.

According to preliminary estimates from the Electric Power Resource Institute (EPRI), the United States has additional water power resource potential of more than 85,000 megawatts (MW). This resource potential includes making efficiency upgrades to existing hydroelectric facilities, developing new low-impact facilities, and using abundant marine and hydrokinetic energy resources. EPRI research suggests that ocean wave and in-stream tidal energy production potential is equal to about $10 \%$ of present U.S. electricity consumption (about 400 terrawatt-hours per year). The greatest of these resources is wave energy, with the most potential in Hawaii, Alaska, and the Pacific Northwest.

The Department of Energy's (DOE's) Water Power Program works with industry, universities, other federal agencies, and DOE's national laboratories to promote the development and deployment of technologies capable of generating environmentally sustainable and cost-effective electricity from the nation's water resources.

\section{Industry Overview}

Since the 1880 s conventional hydropower has generated electricity. During the 1940s, it provided more than one-third of the nation's electricity. Although non-federal entities own the majority of the nation's individual hydropower plants, about half of the nation's hydroelectric generation capacity is owned and operated by federal agencies, most notably the U.S. Army Corps of Engineers and the Department of the Interior's Bureau of Reclamation. DOE works with these

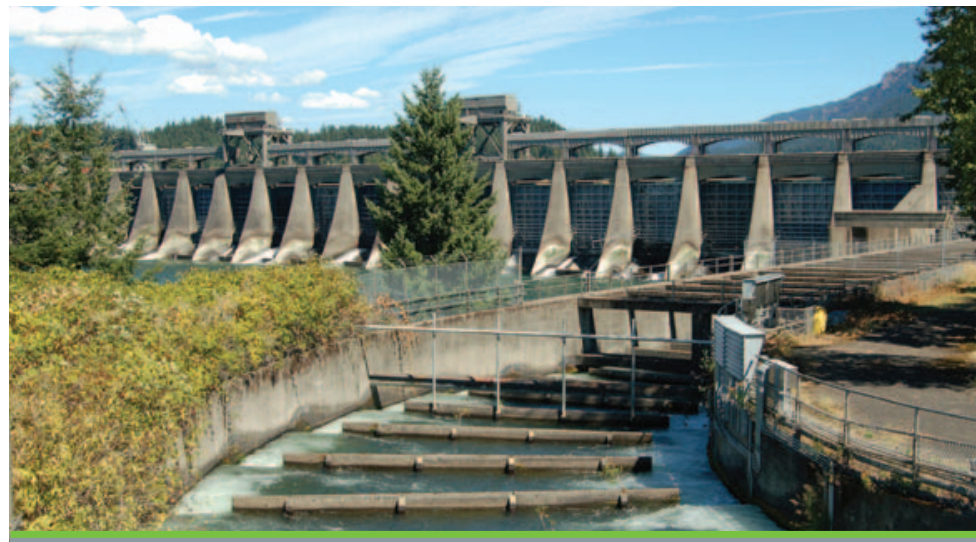

The Bonneville Dam on the Columbia River between Washington and Oregon provides safe passage to migratory fish via its fish ladders while maintaining a capacity rating of more than 1,000 megawatts. Photo from istock/4200712

vagencies, as well as with commercial owners and operators of hydropower dams, to modernize the nation's hydropower facilities with advanced technologies. The hydropower industry is also developing new technologies and deployment methods to add power generation to existing non-powered dams and expand pumped storage hydropower.

The marine and hydrokinetic energy industry is an emerging field with only a handful of demonstration projects operating in U.S. waters. Installing demonstration devices in open-water settings enables technology developers to gather crucial operational and environmental data that are used to refine device designs and establish baseline cost and performance projections. Technology developers have investigated numerous device design approaches to harness different water power resources, and these approaches are beginning to coalesce around a smaller number of designs as the industry matures. Descriptions of some different marine and hydrokinetic technology types can be found in the Water Power Program's Marine and Hydrokinetic Technology Glossary: eere.energy.gov/water/marine_hydro_glossary.html.

\section{Water Program Activities}

The Water Power Program develops advanced water power technologies and accelerates market adoption of these technologies.

\section{Conventional Hydropower}

The Water Power Program conducts applied research and development (R\&D), testing, and demonstration of advanced conventional hydropower technologies to increase generation from hydropower and reduce potential environmental effects. For example, the program funds the Electric Power Research 


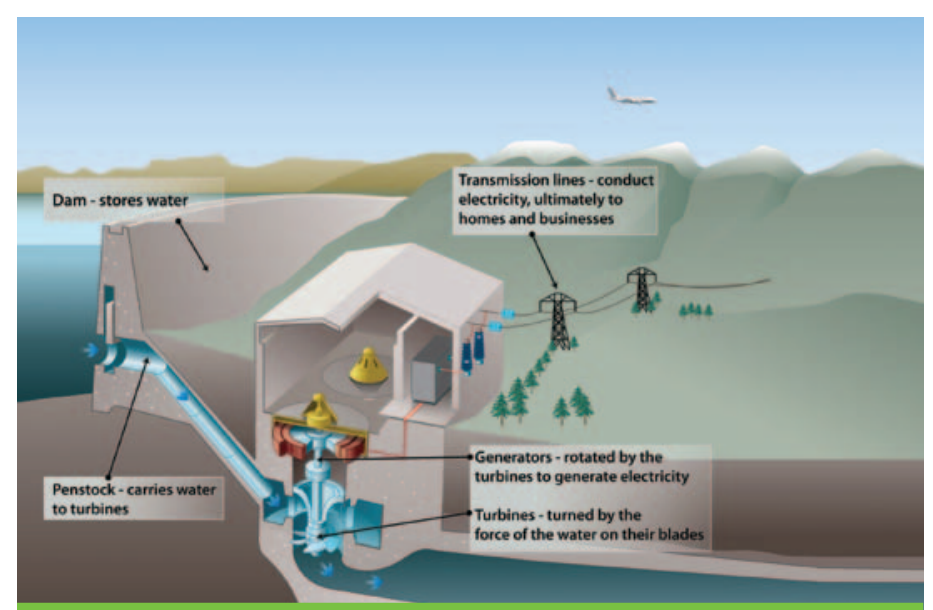

Cross section of conventional hydropower facility that uses an impoundment dam. Illustration by Joshua Bauer, NREL

Institute to finalize the engineering design and develop construction specifications and costs of a fish-friendly hydropower turbine. The program also supports infrastructure modernization at existing hydropower plants, including seven upgrade projects funded with $\$ 30.6$ million from the Recovery Act. Facility upgrades increase generating efficiency and minimize environmental effects of the hydropower facilities. Finally, the program undertakes a range of research and testing activities that provide the scientific basis for improving hydropower technologies, from the development of hardware to software and analytical methods. Hydropower plant operators will ultimately use these products and studies to improve facility power generation capacity and environmental performance.

The Water Power Program reduces the time and costs associated with permitting hydropower projects; better quantifies the potential magnitude, costs, and benefits of hydropower generation; and identifies and addresses other barriers to hydropower deployment. One key aspect of this work is assessing the nation's hydropower resources, including the potential for increased generation and capacity at existing facilities, new pumped storage development, new low-impact and small generation, and powering non-powered dams. Research, development, and deployment of cost-competitive advanced pumped storage technologies for variable renewable integration and transmission system stabilization are among the program's priorities. Another aspect of the program's work is the design, development, and testing of new ways to reduce potential adverse effects of hydropower on fish populations, water quality, and river habitats.

\section{Marine and Hydrokinetic Technologies}

The Water Power Program supports the development and testing of various marine and hydrokinetic systems and components, from proof-of-concept studies to full-scale demonstration projects. In 2010, the program awarded $\$ 37$ million for the R\&D of devices, including wave power buoys, tidal power turbines, oscillating water column wave energy converters, river-instream turbines, and ocean thermal energy conversion components. The program also develops tools and models that support the design, development, and optimization of marine and hydrokinetic devices. These projects will help maximize efficient electricity generation at marine and hydrokinetic power plants while mitigating potential environmental effects. In addition, the program has established university-led National Marine Renewable Energy Centers in the Northwest, Florida, and Hawaii to facilitate in-water testing of marine and hydrokinetic devices and components. These centers will have open-water test berths as well as laboratory facilities that will enable researchers to investigate marine and hydrokinetic devices under real-world conditions.

To accelerate market development, the program works to reduce the time and costs of siting marine and hydrokinetic power projects, and identifies and addresses barriers to deployment. For example, the program is funding studies on the potential effects of marine and hydrokinetic technologies on specific species as well as on aquatic ecosystems. The program is also assessing the potential extractable energy contained in the nation's waves, tides, ocean currents, rivers, streams, and ocean thermal gradients. In addition, the program is developing consistent instrumentation requirements to measure the performance of generation devices. The program is actively engaged with international agencies, research institutions, and businesses to leverage lessons learned and avoid redundant work in the pursuit of developing a viable alternative energy source from the nation's wave, current, and tidal resources.

Finally, the program is conducting economic analyses to quantify the benefits of the widespread deployment of effective and costcompetitive marine and hydrokinetic systems. These analyses include assessing industry R\&D needs and identifying policy mechanisms and market designs that will accelerate deployment.

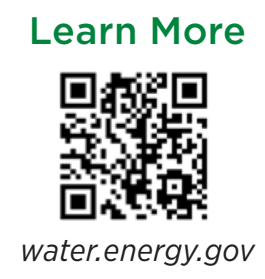

For more information, visit: eere.energy.gov water.energy.gov

DOE/GO-102012-3545 • March 2012

Printed with a renewable-source ink on paper containing at least 50\% wastepaper, including $10 \%$ post consumer waste. 